Dubravka M. Đurić

dubravka.djuric@fmk.edu.rs

\title{
Poetika hibridnih multižanrovskih pesničkih tekstova Ljubomira Micića i Branka Ve Poljanskog
}

\begin{abstract}
Dubravka M., Poetika hibridnih multižanrovskih pesničkih tekstova Ljubomira Micića i Branka Ve Poljanskog (Poetics of Ljubomir Micić and Branko Ve Poljanski's hybrid multigenre poetic texts). „Poznańskie Studia Slawistyczne” 2. Poznań 2012. Adam Mickiewicz University Press, pp. 119-133. ISBN 978-83-232-2409-9. ISSN 2084-3011.

In the text I will focus on Zenitist poetry by Ljubomir Micić and Branko Ve Poljanski. I will construe a new discursive framework, which will make it possible for us to understand their multigenre texts as important items in the national poetry canon. I will contextualize the general characteristics of European avant-garde poetry practices, which were used by Micic and Poljanski in order to interpret the specific place of Zenitism as a general Balkan avantgarde movement, participating in a significant way in the European and world avant-garde.
\end{abstract}

Keywords: avant-garde poetry, hybridity, manifesto, multigenre, performativity

Naša otadžbina bila je najtužnija onda, kada smo se
i mi u njoj morali roditi.

Na početku ovog teksta treba reći da su diskursi istorije književnosti u Srbiji i Hrvatskoj poslednjih pola veka uglavnom postavljali zenitističku poeziju na margine nacionalnih kanona srpske, odnosno hrvatske književnosti ${ }^{2}$. Preciznije rečeno, zenitistička poezija je integrisana ili, pre, asi-

${ }^{1}$ Lj. Micić, B. Ve Poljanski, „Panika pod suncem” - Tragedija balkanske azbuke, u: B. Ve Poljanski, Panika pod suncem, Beograd 1923, str. 4.

${ }^{2} \mathrm{O}$ izrazito kritičkom odnosu prema poeziji Ljubomira Micića videti u: R. Vučković, Avangardna poezija, Banjaluka 1984, str. 198 i C. Milanja, Pjesništvo hrvatskog ekspresionizma, Zagreb 2000, str. 189. 
milovana u pomenute nacionalne kanone, ali u njima ne zauzima središnju poziciju kao značajan identifikacioni model važan za konstrukciju nacionalnog identiteta. Ustrajavanje ovog diskursa govori o nemogućnosti arbitara nacionalnih književnosti da preispitaju i redefinišu ideologije ${ }^{3}$ konstitutivne za diskurse nacionalne istorije književnosti. Na snazi je uverenje da postoji velika Nacionalna Književnost, koja se konstituiše u obliku nacionalnog kanona. Ali kanon ,velikih književnih dela” je mistifikacija koja prikriva činjenicu da je proizvodnja književnih artefakata istorijska praksa, determinisana ideološki, rodno, klasno, rasno itd. ${ }^{4}$ Normativne vrednosti u poeziji se zasnivaju na procenjivanju sledećih kategorija: savršenstvo stila, harmoničnost, jasnost poruke $i$, što je možda najvažnije, bavljenje velikim nacionalnim temama, a istovremeno i velikim temama evropske tradicije, koje su preuzete i prevedene u sistem reprezentacija lokalne nacionalne kulture. Ove teme podrazumevaju i određeni način obrade, pre svega u modusima uspostavljenim u evropskoj tradiciji, i to u zakasnelom klasicizmu, romantizmu i realizmu. Zatim, mit o umetniku-piscu priča o obdarenom pojedincu, koji poseduje snažan kreativni potencijal i u stanju je da ga ispolji, pišući remek-dela nacionalne književnosti. U igru ulaze diskursi o individualnom talentu, tradiciji, genijalnosti i originalnosti ${ }^{5}$. Ali treba istaći da je polje književnosti društveno regulisano i nadzirano, da je konstruisano diskursima moćnih nacionalnih kulturnih institucija društva i njihovih zastupnika (profesora, istoričara književnosti, kritičara, urednika, članova žirija, itd). Otkriti zašto je avangardna književnost na marginama nacionalnog kanona, znači otkriti na kojim se pretpostavkama zasniva kanon. Zato ću se baviti nekim ideološkim predrasudama ugrađenim u pristupe dominantne kritike avangardne poezije, ne bih li konstruisala novi okvir čitanja, koji omogućava da se zenitistička poezija, a posebno poezija Ljubomira Micića i Branka Ve Poljanskog, sa margine nacionalnog kanona postavi u njegovo središte ${ }^{6}$.

\footnotetext{
${ }^{3} \mathrm{O}$ ideologiji nauke o književnosti videti u: M. Juvan, Ideologije primerjalne književnosti: perspektive metropol in periferij, u: Primerjalna književnost v 20. stoletju in Anton Ocvirk, ur. D. Dolinar, M. Juvan, Ljubljana 2008, str. 57-91.

${ }^{4}$ Cf. G. Pollock, About canons and culture wars, u: G. Pollock, Differencing the Canon - Feminist Desire and the Writing of Art's Histories, London-New York 1999.

${ }^{5}$ Cf. D. Đurić, Poezija teorija rod, Beograd 2009, str. 35-46 i 80-82.

${ }^{6}$ Važni interpretatori koji su o zenitizmu pisali pozitivno su Aleksandar Flaker, Irina Subotić, Vida Golubović, Gojko Tešić, Miško Šuvaković. Knjiga L. Grdan, Zenit i simulta-
} 
I mada je radikalna, avangardna, pesnička praksa danas globalno postavljena kao važan domen akademskog bavljenja književnošću, ipak bih naglasila da ona i dalje zauzima marginalno mesto, ne samo u takozvanim malim, već i u imperijalnim kulturama kao što je američka. Pozvaću se na američkog kritičara poezije Michaela Greera, koji je pisao da se radikalne pesničke prakse u nacionalnim kanonima postavljaju u ulogu egzotičnog drugog budući da su 'ekstremne', ili 'eksperimentalne', one potvrđuju postojanje dominantne poetike i njenu prevlast u kulturi. Dakle, ma kako 'iritirajuća' i 'opoziciona' bila, funkcija eksperimentalne poezije u dominantnom toku kulture je da osigura središnji položaj vladajuće (mainstream) umerenomodernističke i visokomodernističke poezije ${ }^{7}$.

\section{Ljubomir Micić: avangardna pesnička praksa, originalnost i konvencije lirske pesme}

Polazim od stava da većina kritičara koji pišu o avangardnoj poeziji, smatra da je poezija Ljubomira Micića puka demonstracija zenitističke poetike. Ovde je aktivirana ideološka pozicija po kojoj pesnik ni u kom slučaju ne treba eksplicitno da objašnjava svoju poeziju. Drugim rečima, sprovedena je stroga podela rada na pesnike-stvaraoce, koji vladaju prvostepenim jezikom (pišu pesme), i kritičare, koji vladaju drugostepenim jezikom, tj. metajezikom (bave se poezijom kao svojim objektom). Ukoliko je pesnik i kritičar, mora delovati u odvojenim diskurzivnim poljima poezije, odnosno, kritike, koja se ne smeju mešati. Po konzervativnim koncepcijama književnosti, žanrovi su strogo definisani i odvojeni. Mnogi pesnici ipak pišu o poeziji i to u obliku poetike kao posebnog žanra. U svakom slučaju, insistira se na čistoti i odvojenosti medija i nenarušavanju konvencija lirske pesme. Na tragu američke kritičarke Marjorie

nizam, Beograd 2010. bavi se nekim od aspekata zenitističke poezije o kojima i ja u ovom tekstu raspravljam. O eksperimentalnoj poeziji u jugoslovenskom kulturnom prostoru pisala sam u tekstu Radical Poetic Practice: Concrete and Visual Poetry in the Avant-garde and Neo-avant-garde, u: Impossible Histories - Historical Avant-gardes, Neo-avant-gardes, and Post-avant-gardes in Yugoslavia, 1918-1991, eds D. Djurić, M. Šuvaković, Cambridge (Massachusetts)-London 2003, str. 64-95.

${ }^{7}$ Navedeno u: D. Đurić, Jezik, poezija, postmodernizam, Beograd 2002, str. 78. 
Perloff, možemo reći da se u takvim, dominantnim, kritičarskim pristupima, avangardna tekstualna proizvodnja ocenjuje sa aspekta norme lirske pesme $^{8}$, a ne s aspekta same avangardne produkcije koja intencionalno narušava čistotu žanrova i stvara jedan, metaforično govoreći, 'hipertekstualni prostor' ${ }^{9}$. U njemu su verbalno i vizuelno podjednako konstitutivni te dolazi do mešanja žanrova, jer se prepliću poezija, proza, drama, esej, manifest itd. Marjorie Perloff je pisala da kritičari koji koriste pojam 'lirika' smatraju da je priroda poezije večna i univerzalna. Pod lirikom oni podrazumevaju da je pesma, kako se Hegel izrazio, ,subjektivni i lični izraz" pesnika, te se avangardna pesnička tekstualnost izostavlja iz definicije pojma lirske pesme. Pojam avangardne pesničke tekstualnosti izvela sam iz poststrukturalističkog pojma tekstualnost, koji je jezički pesnik i teoretičar, Michael Davidson, primenio na postmodernu američku eksperimentalnu jezičku poeziju, jer se time izbegavaju žanrovske podele koje podrazumevaju hijerarhiju žanrova ${ }^{10}$.

Da bi istoričari književnosti pesmu smatrali vrednom, ona mora da ispunjava više uslova, među kojima su zahtev da je kratka, izrazito osećajna i lirski intonirana i da se bavi privatnom sferom pojedinca. Ljubomir Micić se u poeziji najviše udaljio od tog modela, dok je Poljanski u kratkim pesmama zadržao lirski naboj, koji omogućava tradicionalno orijentisanim kritičarima avangarde da njegovu poeziju ipak ocene kao koliko toliko vrednu.

Ako je klasična buržoaska kultura poeziju definisla kao domen izražavanja ličnih osećanja i bavljenja privatnošću lirskog subjekta, avangardna poezija proširuje pojam poezije. Poezija postaje vizuelno-verbalno proizvođenje tekstualnosti, koje u sebe inkorporira različite diskurse. U pitanju je montaža fragmenata često parodiranih lirskih iskaza, svakod-

${ }^{8}$ O konvencijama lirske pesme pisala je Marjorie Perloff. Vide M. Perloff, Pound/ Stevens: Whose Era, u: eadem, The Dance of the Intellect - Studies in the Poetry of the Pound Tradition, Cambridge-New York 1985, 1987.

${ }^{9}$ Kao što o poeziji Stevea McCafferyja, Jacksona Mac Lowa, itd. Jerome Rothenberg i Pierre Joris pišu u smislu kretanja ka kiberpoetici (Poems for the Millennium, Volume Two, From Postwar to Millennium, eds J. Rothenberg, P. Joris, Berkeley 1998, str. 817-829), ja metaforično koristim reč hipertekstualni prostor, kao tip tekstualnosti koji prethodi savremenoj virtuelnoj hipertekstualnosti.

${ }^{10}$ Vide D. Đurić, Jezik, poezija, postmodernizam, str. 50. 
nevnog govora, žargona, medijskih tekstova, političkih diskursa, itd. Lirsko implicira izražavanje osećajnosti posredstvom 'glasa' subjekta koji izgovara pesmu (lirsko ja), te u deridijanskim ${ }^{11}$ terminima možemo govoriti o prisutnosti ili bolje o simulaciji prisutnosti pesnika ili lirskog subjekta posredstvom retorički konstruisanog glasa koji nam se, čini se, 'prisno obraća'. U avangardi, posebno kod autora kakav je Micić, lirsko je u većoj ili manjoj meri odbačeno. Tipično za avangardu, Micić zahteva da se gaji osvetnička mržnja do uništenja cele stare pseudokulture poezije „osećaja” - „emocije” - „lepote”, te zenitističku poeziju definiše kao konstruktivističku. Do nje se dolazi bezuvetno konstruktivno, što znači svesno, određeno i geometrijski (,,zenitističko pesništvo nije rođeno nego stvoreno" i laž je ,da se pesma rađa”, ${ }^{12}$ zenitizam je ,najnoviji balkanski tip konstruktivnog stvaranja") ${ }^{13}$. Odbacivši organističko shvatanje poezije, Micić odbacuje $\mathrm{i}$ analogije sa biološkim procesima i pojmovima rast, harmonija, zaokruženost, koji su, smatra se, preduslov za stvaranje poetske umetničke vrednosti.

Hibridna forma ${ }^{14}$ eksperimentalne avangardne poezije zahteva da uočimo koji su sve umetnički i žanrovski kodovi uvedeni u interakciju. Činjenica da zenitisti pišu na početku svojih knjiga manifeste, govori o potrebi da se sopstvena pozicija u nacionalnoj kulturi nedvosmisleno eksplicira i da se diskurzivno odredi ideologija umetničkog rada. Manifest ima dvostruku funkciju. Autor u njemu objašnjava svoje pozicije, definiše poetiku i kontekst umetničkih paradigmi u kojima deluje. I sam manifest je multižanrovska forma, konstituiše se kao hibridni prostor, jer pesnici koriste strategije poezije, proze, eseja, suočavaju vizuelno i verbalno. Manifest je izazito performativan, jer izriče $\mathrm{i}$ istovremeno demonstrira poetičke principe i pozicije. Govori se i o tome da u avangardi tekst postaje "partitura' za glasovnu izvedbu (većina zenitističkih, kao i drugih avangardnih manifesta, i drugih tekstova, bila je javno čitana, u slučaju „Zenita” na

${ }^{11}$ Pojam 'deridijansko' u ovom tekstu izveden je iz američke teorije i kritike poezije koja se bavi avangardnom poezijom 20. i 21. stoleća. Relevantni autori su Charles Bernstein, Michael Davidson, Jed Rasula, Barrett Watten, Rachel Blau DuPlessis, itd.

${ }^{12} \mathrm{Lj}$. Micić, Kategorički imperativ zenitističke pesničke škole, u: idem, Kola za spasavanje, Zagreb 1922, str. 5.

${ }^{13}$ Ibidem, str. 3.

${ }^{14}$ Pojmom hibridne forme označavam hibridne tekstualne prakse, koje koriste strategije više žanrova, opširnije videti u: D. Đurić, Poezija teorija rod, str. 390-392. 
zenitističkim večernjama). Kao i svaki avangardni tekst, zenitistički manifesti i poezija su performativni, jer za oko i uho čitaoca/slušaoca priređuju jedan vizuelno-zvučni događaj, u kojem pisac ne deluje samo značenjima, već materijalnim, vizuelnim i zvučnim izvođenjima teksta. Vizuelnost teksta obuhvata upotrebu crteža, fotografija i raznovrsne tipografije. Zvukovni nivo teksta se realizuje kada se tekst izvodi čitanjem na sceni ili na ulici, kao i kada ga čitalac/čitateljka u sebi čitaju, uživajući u zvukovnim ponavljanjima koji svako od njih može da 'čuje', tj. realizuje u svojoj imaginaciji ${ }^{15}$. Koristeći deridijansku terminologiju, možemo reći da avangardna poezija/avangardni tekstualni eksperiment, aktivira označitelje teksta, jer radi sa zvukom i grafizmom.

Tvrdnja da poezija Ljubomira Micića nema umetničku vrednost jer je puko demonstriranje njegovih manifesta, zasniva se na još jednoj apriornoj propoziciji. U pitanju je uverenje da nikakav svestan koncept ne sme prethoditi umetničkoj kreaciji jer umanjuje, štaviše, šteti umetničkoj realizaciji pesme, drame, proze, itd. Ova konzervativna kritičarska pozicija prikriva činjenicu da koncept uvek prethodi realizaciji umetničkog dela. Uverenje da književno delo prethodi konceptima i teoretizacijama je konstrukcija, tj. proizvedena teorijska pozicija, koja svojim apriornim, normativnim zahtevima strogo definiše kako proizvodnju tako i recepciju umetničkog dela.

Neki interpretatori smatraju da je Micićeva poezija imitatorska i suvoparna i da on ni kao pesnik ni kao tvorac zenitističkog pokreta nije originalan. Tvrdi se da su, na primer, italijanski futuristi i drugi avangardisti pre njega zagovarali odbacivanje evropske tradicije. Ali mora se imati na umu da razlozi zbog kojih su to učinili nisu isti i da pojam stare književnosti i umetnosti ne znači u svim kontekstima isto. Italijanski futuristi su odbacili prošlost, definišući Italiju kao zemlju ispunjenu starinama, koje onemogućavaju da se kultura dalje razvija u skladu sa novim vremenom. U kontekstu u kojem je Micić stvarao, odbaciti staru kulturu i staru poeziju, značilo je odbaciti ,jugoslovensku predpotopnu fosilnu poeziju" ${ }^{16}$. Micić je pisao: „Ah divna je ta vaša latinska ljubav / Uvoz kulturnih otpadaka u kolonije «divljaka»"17.

${ }^{15} \mathrm{O}$ performativnim aspektima poezije videti tekstove u knjizi Close Listening Poetry and the Performed Word, ed. C. Bernstein, Oxford-New York 1998.

${ }^{16} \mathrm{Lj}$. Micić, Kategorički imperativ..., str. 3.

${ }^{17}$ Idem, Kola za spasavanje, str. 22. 
Na početku teksta Vanumna poezija i antievropa, Micić piše: „Vanum je raj «ludaka» u koji se ulazi nepisanom putnicom talenta: duhovno nag i čist - kao kap sunca. Ja sam ušao i borbom preko leševa evropske klasike i nacionalne poezije - ostaviv za sobom svlak svoje stare poezije u preziranju samog sebe u sebi i u drugim pesnicima"18. Pojam 'vanum' ima svoju analogiju u ruskom kubofuturističkom pojmu zauma. Ni ovde ne treba govoriti o Micićevom 'plagijatorstvu', jer bi to značilo da smatramo da postoji nešto izvorno, prvobitno. Ali, sledeći deridijansku poziciju, prihvatimo da ne postoji ništa što je izvorno i prvobitno. Stoga možemo reći da ljudi u različitim društvenim kontekstima konstruišu i redefinišu određene ideje i prakse. Potrebno je proučiti šta one u konkretnim društvenim i istorijskim prilikama znače i kako su ih njihovi protagonisti definisali i praktikovali.

Micić piše o političkim rugobama Evrope, od kojih izdvaja imperijalizam i kapitalizam, čiji smo „mi” robovi oduvek bili, a sa tim je povezano i naše kulturno ropstvo, te se on zalaže za antievropu: „Hoću da zenitističkom poezijom budemo prva brana evropskoj dekadenciji na Balkanu". Pesnik antievrope protivi se evropskom kolonijalizmu i smatra da se balkanska rasa mora pobuniti i podići revoluciju: revoluciju duha. Ovde ću se poslužiti analizom Paula Peppisa. U knjizi Književnost, politika i engleska avangarda 1901-1918 Peppis je pisao da je doba avangarde prikladno proglašeno „Dobom Nacionalizma i Dobom Imperije” ${ }^{19}$. Neobuzdane proklamacije italijanskih futurista i britanskih vorticista ,potvrđuju da su istorijske avangarde, kao i zapadna kultura uopštenije tokom ovog perioda, bile, kao što je to Edward Said rekao, «javno i neprikriveno deo» «imperijalnog procesa» ${ }^{, 20}$. Uprkos težnji ,da transformišu ustanovljenu umetnost i političke institucije, uprkos kosmopolitskom interesu da učestvuju u internacionalnom naporu estetske i društvene revolucije, evropske avangardne umetničke grupe su posebno bile motivisane da uzdignu prestiž sopstvene nacije" ${ }^{\text {21 }}$. Britanski BLAST je bio uhvaćen u kontradikcijama između zala-

\footnotetext{
${ }^{18}$ Idem, Vanumna poezija i antievropa, u: Lj. Micić, Antievropa, Zagreb 1926, nenumerisano.

${ }^{19}$ P. Peppis, Literature, Politics, and the English Avant-Garde - Nation and Empire, 1901-1918, Cambridge 2000, str. 4.

${ }^{20}$ Ibidem, str. 5 .

${ }^{21}$ Ibidem, str. 6.
} 
ganja vorticizma za transformaciju društva i kulturnog elitizma i napora da dobije podršku za nacionalnu konsolidaciju. Vorticizam kao avangardni pokret delimično je težio da se pozicionira kao instrument nacionalne politike. Marinetti je slične kontradikcije pokušao da reši stvaranjem populističkog avangardnog pokreta, koristeći reklamu i tehnike promovisanja da bi zadobio masovnu publiku ${ }^{22}$. U kontekstu problematike kojom se Peppis bavi, zenitističku avangardnu poeziju i zenitizam u celini možemo shvatiti kao imperativni zahtev balkanskim pesnicima i umetnicima da u arenu aktuelnog sistema svetske književnosti ${ }^{23}$ po prvi put uđu sa 'originalnim' balkanskim umetničkim, odnosno, pesničkim pokretom. U tu svrhu Micić je izgradio poseban 'primitivistički diskurs', karakterističan za avangar$\mathrm{de}^{24}$. Pisao je: „ZENITIZAM JE NAJBUNTOVNIJI ČIN MLADE BAR-

BARSKE RASE". Zenitizam je ekspanzija barbarske snage golog čoveka. On omogućava da se po drugi put unište smrdljivi plodovi evropske pseudokulture i civilizacije. „To već čine barbari evrope, MI barbari evrope činimo to veselo." A na tragu Micićevih ideja Branko Ve Poljanski na početku „Manifesta”, iz knjige Tumbe, konstruiše mitsku sliku avangardnog balkanskog pisca/umetnika.

\section{Branko Ve Poljanski, Balkanac kao autentični divljak Evrope i filmroman kao multižanrovski poduhvat}

Zapadni umetnici su smatrali da je potrebno da se otuđeni gradski čovek vrati prirodi i postane ponovo divljak, te su odlazili iz grada na selo ili u daleke egzotične predele da bi obnovili stvaralačku energiju ${ }^{25}$. Nasuprot njima, Poljanski sebe konstruiše kao 'istinskog', 'autentičnog' divljaka. U „Manifestu”, pisanom u Parizu 1926. godine, poredeći pozicije zapadnog i balkanskog umetnika, on koristi fikcionalni pripovedni ton:

Rečica koja tecijaše posred sela moga malog, nije se zvala Sena. U onoj kućici na obali, pored malog drvenog mosta, nije stanovao Sezan. Tamo na onome brdu ze-

${ }^{22}$ Ibidem, str. 93.

${ }^{23}$ O pojmu svetski sistem književnosti videti M. Juvan, Svetska književnost $(i)$ i periferije, prevela sa engleskog M. Ivić, „Polja” br. 471, 2011, str. 116-125.

${ }^{24}$ Vide D. Đurić, Poezija teorija rod, str. 335-343.

${ }^{25}$ Ibidem. 
lenom ne bijaše nijedan muzej ,,večnih dela”. Tamo beše gora i šuma puna zveradi i tekućeg zlata što se s rosom jutarnjom pomešalo.

Rečica koja tecijaše pored sela moga malog, zvaše se Maja. Nije beznačajno napomenuti, da Maja na staroindijskom ima dva tako različna i jedinstvena značenja; Maja znači iluzija i zemlja. U Maji sam kupao svoje telo i duh svoj, te je on danas tako čist. Moj duh, koji nosi danas šimi-cipele, da bi ponova mogao prohodati go i bos ${ }^{26}$.

Nakon što je napravio razliku između malog sela u kojem je rođen i velike metropole kakav je Pariz, Poljanski definiše „vesele barbare sa Balkana” nasuprot umetnicima Zapada. Umetnicima Zapada obraća se sledećim rečima:

Kad ste pronašli crnačku plastiku, besvesno ste se radovali zenitizmu, koga niste poznavali, ali radost nije dugo trajala, jer čega se dotakne spekulativna ruka novog evropejca, to je sve izgubljeno za novo čovečanstvo. Od crnačke plastike, koja je nikla iz golog duha ,divljeg” čoveka, učinili ste vi neku evropsku limonadu, koja nema nikakova ukusa a reakcija je na taj nektar duha - bljuvanje.

Budite zenitisti. Stvarajte dela, koja su velika za svekoliko čovečanstvo, a zaboravite vašu estetiku, koja ne znači ništa ${ }^{27}$.

Zenitisti su jedini pravi evropski divljaci. Konstruišući ideologiju zenitističkog slikarstva, suprotstavlja ga buržoaskom modernizmu u njegovom najvažnijem žanru: slikanju aktova. Ismevajući buržoaski modernizam i njegovu umetničku ispraznost, Poljanski ismeva i apstraktnu umetnost. Maljevičevska apstrakcija po njemu je kraj jedne linije slikarstva:

Očevidno je, da je jedna sramna istorijska rabota, došla u ćorsokak estetske teorije larpurlartizma i ne može dalje ni za jedan korak. Kad su neki ruski šaljivčine, neosporno duhoviti, pokrenuli

\section{Nulpunktizam}

u slikarstvu, t.j. belo na belom i crno na crnom, znalo se da to znači kraj jedne slikarske kulture, jedne istorijske zablude i jedne očite akrobatske gluposti, do koje je dovela teorija

\section{Larpurlara $^{28}$.}

\footnotetext{
${ }^{26}$ B. Ve Poljanski, Tumbe, Beograd 1926, str. 7-8.

${ }^{27}$ Ibidem, str. 9.

${ }^{28}$ Ibidem, str. 10-11.
} 
Modernističku ideologiju autonomije umetničkog dela i modernističko usredsređivanje umetnosti na sopstveni jezik, Poljanski opisuje smenjivanjem kratkih rečenica kojim sugeriše brzi ritam kao u poeziji: „Slika je, kažu, svet za sebe. Apsolutno delo. Čisto zlato. Večno delo. Muzejsko delo”. A zenitista kaže: „Slika je glupost za sebe. Apsolutna glupost. Čista glupost. Večna glupost. Muzejska glupost" ${ }^{\prime 29}$. Ovoj i ovakvoj umetnosti Poljanski suprotstavlja umetnost pokretnih slika i zenitistima poručuje „Idite u bioskop, gde ćete najbolje osetiti, relativnost vaših «večnih dela». Naučite se od filma brzini izmene mesta i prostora, a da to filmsko čudo ipak stoji na čvrstoj osnovici jedne jedinstvene ideje, koja nije i ne može biti tendenciozna” ${ }^{30}$. U nastavku se pita: „Zato su Baster Kiton, Šarlo, Duglas i mnogi ostali, veći dramatičari od Šekspira? Vrlo prosto. Oni su intuitivno osetili relativnost mesta, vremena i prostora. Oni su u dramaturgiji našli

$$
\begin{aligned}
& \text { 7. dimenziju } \\
& \text { film } \\
& \text { brzina"31. }
\end{aligned}
$$

U nastavku ću analizirati filmroman 77 samoubica Branka Ve Poljanskog, kao izuzetno ostvarenje jugoslovenskog avangardnog tekstualizma, čija je odlika hibridna, multižanrovska forma.

Poljanski je smatrao, što je tipično za avangardistu, da je filmska umetnost značajnija od apstraktnog slikarstva Braquea, Legera ili Maljeviča, da su filmski umetnici značajniji od klasika. Filmsku umetnost Poljanski opisuje kao savremenu dramsku formu. O značaju ekspresionističkog filma za Poljanskog pisao je Aleksandar Petrov. Petrov je ocenio da je roman 77 samoubica, ,nov u kontekstu srpske, a i jugoslovenske književnosti tog vremena, nastao na liniji tada žive i uticajne ekspresionističke proze, ali još više ekspresionističkog filma" ${ }^{\text {"32 }}$. Kao i drugi zenitisti poput Micića, Marijana Mikca i Boška Tokina, Poljanski je bio veliki poštovalac sedme umetnosti. Dobro je poznavao istoriju filma i pratio je njen

${ }^{29}$ Ibidem, str. 11.

${ }^{30}$ Ibidem.

${ }^{31}$ Ibidem

${ }^{32}$ A. Petrov, Branko Ve Poljanski i njegova „Panika pod suncem”, u: B. Ve Poljanski, Panika pod suncem, Tumbe, Crveni petao, priredio i studiju napisao A. Petrov, BeogradGornji Milanovac 1988, str. L-LI. 
razvoj dvadesetih godina 20. veka. Izdavao je „Kinofon”, ,reviju za filmsku kulturu”, u kojoj je u rubrici „Film-roman” objavio prevode „fantastične filmske priče" H. Vehera pod naslovom Dnevnik doktora Hedersona, i „fantastične filmpriče” V. Hajnriha pod naslovom Bijesna lješina. Zanimljivo je kako se 'umetnost reči' transformiše pod uticajem filmske umetnosti, tj. kako se strategije filmske montaže i efekti filma transponuju u eksperimentalni roman. Termin 'roman' je uslovna žanrovska odrednica, a preciznija metaforična odrednica bi bila „filmroman”. U pomenutom „Manifestu” u knjizi Tumbe Poljanski je, videli smo, savetovao savremenim umetnicima i piscima da se nauče od filmske umetnosti brzini izmene mesta i prostora, drugim rečima, treba ,intuitivno osetiti relativnost mesta, vremena i prostora" ${ }^{\text {"33. }}$. Te principe će primeniti u filmromanu 77 samoubica - Neverovatna ljubavna zbitija gospodina Nikifora Mortona. Veoma brz nadfantastičan roman.

Filmroman 77 samoubica objavljen je 1923. godine. U pitanju je avangardni multižanr, hibridni oblik koji u diskontinualnoj pripovesti filmično suočava prozne i poetske postupke. Ovaj apstraktno-ekspresionističko-futurističko-konstruktivistički poduhvat pisan je prenošenjem filmske tehnike u medij pisane reči. Na koricama je apstraktno vizuelno delo, a na samom početku romana nalazi se fotografija Ajfelovog tornja kao simbol modernosti tog vremena. Glavni junak Nikifor Morton je zagonetna figura čoveka koji (možda) traga za znanjem, nasleđena iz nemačkog romantizma, a ujedno je i figura savremenog čoveka koji traga za smislom i želi da prevaziđe svakodnevicu jednog materijalističkog doba ${ }^{34}$. Poljanski referira, na primer, na mit o Faustu, na hrišćanstvo sa svojim metafizički postavljenim antipodima dobra i zla, a konstruiše i druge binarne opozicije, karakteristične za kulture Zapada, među kojima su: Bog i Lucifer (dobro i zlo), građenje i uništavanje, muški i ženski princip, pojedinac i masa.

Poljanski koristi postupke razvijene u futurizmu, koji je slavio brzinu i težio da u mediju slikarstva i u mediju umetnosti reči, podražava mogućnosti koje su otvorili fotografija i film. Utisak filmske dinamičnosti Poljanski postiže brzim smenjivanjem reči, fraza i rečenica. Istovremeno, dužina rečenica, reči i fraza, kao i promena kadra, sugerišu promenu ritma i ose-

${ }^{33}$ B. Ve Poljanski, Manifest - Fragment iz velikog manifesta svim narodima globa, u: idem, Tumbe, str. 11.

${ }^{34}$ Vide D. Đurić, Jezik, poezija, postmodernizam, str. 140. 
ćanja, signalizirajući i promenu žanrovskih kodova. U autopoetičkim (meta)formulacijama objašnjava svoj postupak. Tako na jedom mestu nailazimo na iskaz: „Centrala za proizvodnju reči velike napetosti radila je bez

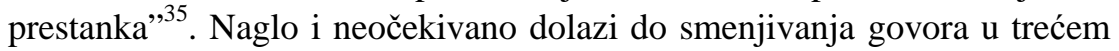
licu sa govorom u prvom licu. Poljanski eksperimentiše prozom i pesmom u prozi, važnu ulogu ima smenjivanje ritma proze i ritma poezije, koristi ponavljanja, paralelizme, dužinu sekvenci (sekvenca može biti rečenica ili stih). Evo nekoliko primera:

Kućo. Kamena lađo. Propadni. Ja. Nikifor Morton ne mogu više živeti. - Moj život ne treba ni svetu ni meni. Moj život je sprektralno rasipanje u dane i noći. Život moj laž je u blatu istina.

Noć teče kroz šuplja okna i zaleva telo eksperimentatora Nikifora.

Tišina je mirisala na sveže jorgovane

$$
\begin{aligned}
& \text { na vatru } \\
& \text { na brzinu } \\
& \text { na benzin }
\end{aligned}
$$

na transcendentalne strahote

na umornost

na ludačku dosadu koncentracije

na beskrajnu modrinu

na strvinu

na leševe

na revoluciju

na veselje žalosno

na krv

Noć je morila oči Mortonove. - Očima je ispio poslednje trakove svetla na suprotnom prozoru. Sklopile su se. Centrala za proizvodnju reči velike napetosti radila je bez prestanka ${ }^{36}$.

Oslikavajući dinamiku urbanog života u gradu, prema kojoj je ambivalentan (istovremeno i pozitivan i kritičan), Poljanski ispisuje kako ,promena juri vanumnom brzinom, ${ }^{, 37}$, ističe da je ovde u pitanju „,mozgovni radiogram” ili „Iz daljine se čulo potmulo brujanje 77 motora Mortonovih

${ }^{35}$ B. Ve Poljanski, 77 samoubica - Neverovatna ljubavna zbitija gospodina Nikifora Mortona, Zagreb 1923, str. 9.

${ }^{36}$ Ibidem, str. 9.

${ }^{37}$ Ibidem, str. 12. 
aeroplana. Aerodrom beše van grada". Navedene fraze referiraju na ruski kubofuturizam i zaumni jezik i na Marinettijevu bežičnu imaginaciju. Na ekspresionizam ukazuje opis: „Pored kola koracaju nekakove stare groteske. - Svet kao groteska”, ${ }^{\text {, }}$. Opisujući Mortona kao multipilicirani lik, Poljanski piše:

Na svim kontinentima urušilo se po nekoliko Mortonovih aeroplana na 77 aerodroma. 77 telesa izašlo je iz tih aeroplana u 77 gradova. Sedamdesetsedmorica neobičnih posetnika bili su

On

Nikifor Morton.

Morton je stao na 77 trgova. Zamislio se bezumno daleko. Stoji. Minutu. Čas. Časove. Do večera. Nepomično. Kameni čovek. To je bilo na centralnim trgovima u ovih 77 gradova $^{39}$.

Sledi spisak od 77 gradova među kojima su Tokio, Okakun, Beograd, Pariz, Bankok, Vin, Teheran, Katan, Čikego, Jerusalim, Sofija, Koban, itd, itd. Postavljajući male, balkanske metropole u istu ravan sa velikim, Poljanski ukida razlike između centara i periferija.

\section{Zaključak}

Pošla sam od teze da je avangardna poezija na marginama nacionalnih kanona, jer se pri njenoj asimilaciji radikalni aspekti pesničkog diskursa 'pripitomljavaju'. To znači da se u istoriji nacionalne poezije avangarda konstruiše tako da se saobražava kanonu kojim dominira lirska poezija. Avangarda u kanonu funkcioniše kao egzotični drugi koji potvrđuje središnje mesto delima koja pripadaju formacijama umerenog ili visokog modernizma.

Usredsredila sam se na poeziju i poetiku Ljubomira Micića, budući da je njegov rad najproblematičniji za stvaraoce nacionalnog kanona. On se najteže može asimilirati, jer je Micić zenitističku avangardu poetiku u svojoj poeziji sproveo do krajnjih konsekvenci. Zagovarajući tezu da se radikalna pesnička praksa procenjuje sa aspekta konvencija lirske pesme,

\footnotetext{
${ }^{38}$ Ibidem, str. 15 .

${ }^{39}$ Ibidem, str. 18.
} 
pokazala sam koje su ideologije operativne u tom procenjivanju i kako avangardna poezija, posebno u radu Ljubomira Micića, dramatično odstupa od normi lirske pesme. Mada su istoričari avangardne poezije pesme Branka Ve Poljanskog pozitivnije ocenili u odnosu na Micića, činilo mi se da je izvan fokusa ostao njegov multižanrovski filmroman, jer, kao duga, hibridna forma, odstupa od konvencija kratke lirske pesme.

U vremenu kada se pesnički eksperiment sa novim medijima globalno postavlja kao značajan, bilo je potrebno reinterpretirati rad zenitista Ljubomira Micića i Branka Ve Poljanskog. Ukazujući na predrasude dominantne kritike, koja ih postavlja na margine pesničkog kanona, ukazala sam i na značenjske odlike zenitističkog pesničkog diskursa, koji ga odvaja od drugih sličnih pokreta koji su delovali između dva svetska rata.

\section{Literatura}

\section{Primarna}

Micić Lj., Branko Ve Poljanski: „Panika pod suncem” - Tragedija balkanske azbuke, u: B. Ve Poljanski, Panika pod suncem, Beograd 1923.

Micić Lj., Kategorički imperativ zenitističke pesničke škole, u: Lj. Micić, Kola za spasavanje, Zagreb 1922.

Micić Lj., Vanumna poezija i antievropa, u: Lj. Micić, Antievropa, Zagreb 1926.

Poljanski B. Ve., 77 samoubica - Neverovatna ljubavna zbitija gospodina Nikifora Mortona, Zagreb 1923.

Poljanski B. Ve, Tumbe, Beograd 1926.

\section{Sekundarna}

Close Listening - Poetry and the Performed Word, ed. Ch. Bernstein, Oxford-New York 1998.

Grdan L., Zenit i simultanizam, Beograd 2010.

Đurić D., Jezik, poezija, postmodernizam, Beograd 2002.

Đurić D., Poezija teorija rod, Beograd 2009.

Juvan M., Ideologije primerjalne književnosti: perspektive metropol in periferij, u: Primerjalna književnost v 20. stoletju in Anton Ocvirk, ur. D. Dolinar, M. Juvan, Ljubljana 2008. 
Juvan M., Svetska književnost(i) i periferije, prevela sa engleskog M. Ivić, „Polja” br. 471, 2011, str. 116-125.

Milanja C., Pjesništvo hrvatskog ekspresionizma, Zagreb 2000.

Perloff M., Pound/Stevens: Whose Era, u: M. Perloff, The Dance of the Intellect Studies in the Poetry of th Pound Tradition, Cambridge-New York 1985, 1987.

Peppis P., Literature, Politics, and the English Avant-Garde - Nation and Empire, 1901-1918, Cambridge 2000.

Petrov A., Branko Ve Poljanski i njegova „Panika pod suncem”, u: B. Ve Poljanski, Panika pod suncem, Tumbe, Crveni petao, priredio i studiju napisao A. Petrov, Gornji Milanovac 1988.

Poems for the Millennium, Volume Two, From Postwar to Millennium, eds J. Rothenberg, P. Joris, Berkeley 1998.

Pollock G., About canons and culture wars, u: G. Pollock, Differencing The CanonFeminist Desire and the Writing of Art's Histories, London-New York 1999.

Radical Poetic Practice: Concrete and Visual Poetry in the Avant-garde and Neo-avant-garde, u: Impossible Histories - Historical Avant-gardes, Neo-avantgardes, and Post-avant-gardes in Yugoslavia, 1918-1991, eds D. Đurić, M. Šuvaković, Cambridge (Massachusetts)-London 2003, 2006, str. 64-95.

Vučković R., Avangardna poezija, Banjaluka 1984. 
